\title{
Coupled coincidences for multi-valued contractions in partially ordered metric spaces
}

N Hussain and A Alotaibi

* Correspondence: aalotaibi@kau.
edu.sa
Department of Mathematics, King
Abdulaziz University, P.O. Box
80203, Jeddah 21589, Saudi Arabia

\begin{abstract}
In this article, we study the existence of coupled coincidence points for multi-valued nonlinear contractions in partially ordered metric spaces. We do it from two different approaches, the first is $\Delta$-symmetric property recently studied in Samet and Vetro (Coupled fixed point theorems for multi-valued nonlinear contraction mappings in partially ordered metric spaces, Nonlinear Anal. 74, 4260-4268 (2011)) and second one is mixed $g$-monotone property studied by Lakshmikantham and Ćirić (Coupled fixed point theorems for nonlinear contractions in partially ordered metric spaces, Nonlinear Anal. 70, 4341-4349 (2009)).

The theorems presented extend certain results due to Cirić (Multi-valued nonlinear contraction mappings, Nonlinear Anal. 71, 2716-2723 (2009)), Samet and Vetro (Coupled fixed point theorems for multi-valued nonlinear contraction mappings in partially ordered metric spaces, Nonlinear Anal. 74, 4260-4268 (2011)) and many others. We support the results by establishing an illustrative example.

2000 MSC: primary 06F30; 46B20; 47E10.

Keywords: coupled coincidence points, partially ordered metric spaces, compatible maps, multi-valued nonlinear contraction mappings
\end{abstract}

\section{Introduction and preliminaries}

Let $(X, d)$ be a metric space. We denote by $C B(X)$ the collection of non-empty closed bounded subsets of $X$. For $A, B \in C B(X)$ and $x \in X$, suppose that

$$
D(x, A)=\inf _{a \in A} d(x, a) \quad \text { and } \quad H(A, B,)=\max \left\{\sup _{a \in A} D(a, B), \sup _{b \in B} D(b, A)\right\} .
$$

Such a mapping $H$ is called a Hausdorff metric on $C B(X)$ induced by $d$.

Definition 1.1. An element $x \in X$ is said to be a fixed point of a multi-valued mapping $T: X \rightarrow C B(X)$ if and only if $x \in T x$.

In 1969, Nadler [1] extended the famous Banach Contraction Principle from singlevalued mapping to multi-valued mapping and proved the following fixed point theorem for the multi-valued contraction.

Theorem 1.1. Let $(X, d)$ be a complete metric space and let $T$ be a mapping from $X$ into $C B(X)$. Assume that there exists $c \in[0,1)$ such that $H(T x, T y) \leq c d(x, y)$ for all $x, y$ $\in X$. Then, $T$ has a fixed point.

The existence of fixed points for various multi-valued contractive mappings has been studied by many authors under different conditions. In 1989, Mizoguchi and Takahashi [2] proved the following interesting fixed point theorem for a weak contraction. 
Theorem 1.2. Let $(X, d)$ be a complete metric space and let $T$ be a mapping from $X$ into $C B(X)$. Assume that $H(T x, T y) \leq \alpha(d(x, y)) d(x, y)$ for all $x, y \in X$, where $\alpha$ is a function from $[0, \infty)$ into $[0,1)$ satisfying the condition $\limsup _{s \rightarrow t^{+}} \alpha(s)<1$ for all $t \in[0$, $\infty)$. Then, $T$ has a fixed point.

Let $C L(X):=\{A \subset X \mid A \neq \Phi, \bar{A}=A\}$, where $\bar{A}$ denotes the closure of $A$ in the metric space $(X, d)$. In this context, Cirić [3] proved the following interesting theorem.

Theorem 1.3. (See [3]) Let $(X, d)$ be a complete metric space and let $T$ be a mapping from $X$ into $C L(X)$. Let $f: X \rightarrow \mathbb{R}$ be the function defined by $f(x)=d(x, T x)$ for all $x \in$ $X$. Suppose that $f$ is lower semi-continuous and that there exists a function $\varphi:[0,+\infty)$ $\rightarrow[a, 1), 0<a<1$, satisfying

$$
\limsup _{r \rightarrow t^{+}} \phi(r)<1 \quad \text { for each } t \in[0,+\infty) .
$$

Assume that for any $x \in X$ there is $y \in T x$ satisfying the following two conditions:

$$
\sqrt{\phi(f(x))} d(x, y) \leq f(x)
$$

such that

$$
f(y) \leq \phi(f(x)) d(x, y) .
$$

Then, there exists $z \in X$ such that $z \in T z$.

Definition 1.2. [4] Let $X$ be a non-empty set and $F: X \times X \rightarrow X$ be a given mapping. An element $(x, y) \in X \times X$ is said to be a coupled fixed point of the mapping $F$ if $F$ ( $x$, $y)=x$ and $F(y, x)=y$.

Definition 1.3. [5] Let $(x, y) \in X \times X, F: X \times X \rightarrow X$ and $g: X \rightarrow X$. We say that $(x, y)$ is a coupled coincidence point of $F$ and $g$ if $F(x, y)=g x$ and $F(y, x)=$ gy for $x, y \in X$.

Definition 1.4. A function $f: X \times X \rightarrow \mathbb{R}$ is called lower semi-continuous if and only if for any sequence $\left\{x_{n}\right\} \subset X,\left\{y_{n}\right\} \subset X$ and $(x, y) \in X \times X$, we have

$$
\lim _{n \rightarrow \infty}\left(x_{n}, y_{n}\right)=(x, y) \Rightarrow f(x, y) \leq \liminf _{n \rightarrow \infty} f\left(x_{n}, y_{n}\right) .
$$

Let $(X, d)$ be a metric space endowed with a partial order and $G: X \rightarrow X$ be a given mapping. We define the set $\Delta \subset X \times X$ by

$$
\Delta:=\{(x, y) \in X \times X \mid G(x) \preccurlyeq G(y)\} .
$$

In [6], Samet and Vetro introduced the binary relation $R$ on $C L(X)$ defined by

$$
A R B \Leftrightarrow A \times B \subseteq \Delta,
$$

where $A, B \in C L(X)$.

Definition 1.5. Let $F: X \times X \rightarrow C L(X)$ be a given mapping. We say that $F$ is a $\Delta$-symmetric mapping if and only if $(x, y) \in \Delta \Rightarrow F(x, y) R F(y, x)$.

Example 1.1. Suppose that $X=[0,1]$, endowed with the usual order $\leq$. Let $G:[0,1] \rightarrow$ $[0,1]$ be the mapping defined by $G(x)=M$ for all $x \in[0,1]$, where $M$ is a constant in $[0,1]$. Then, $\Delta=[0,1] \times[0,1]$ and $F$ is a $\Delta$-symmetric mapping.

Definition 1.6. [6] Let $F: X \times X \rightarrow C L(X)$ be a given mapping. We say that $(x, y) \in X$ $\times X$ is a coupled fixed point of $F$ if and only if $x \in F(x, y)$ and $y \in F(y, x)$. 
Definition 1.7. Let $F: X \times X \rightarrow C L(X)$ be a given mapping and let $g: X \rightarrow X$. We say that $(x, y) \in X \times X$ is a coupled coincidence point of $F$ and $g$ if and only if $g x \in F(x, y)$ and $g y \in F(y, x)$.

In [6], Samet and Vetro proved the following coupled fixed point version of Theorem 1.3 .

Theorem 1.4. Let $(X, d)$ be a complete metric space endowed with a partial order $\leqslant$. We assume that $\Delta \neq \emptyset$, i.e., there exists $\left(x_{0}, y_{0}\right) \in \Delta$. Let $F: X \times X \rightarrow C L(X)$ be a $\Delta$-symmetric mapping. Suppose that the function $f: X \times X \rightarrow[0,+\infty)$ defined by

$$
f(x, y):=D(x, F(x, y))+D(y, F(y, x)) \text { for all } x, y \in X
$$

is lower semi-continuous and that there exists a function $\varphi:[0, \infty) \rightarrow[a, 1), 0<a<1$, satisfying

$$
\limsup _{r \rightarrow t^{+}} \phi(r)<1 \quad \text { for each } t \in[0,+\infty) .
$$

Assume that for any $(x, y) \in \Delta$ there exist $u \in F(x, y)$ and $v \in F(y, x)$ satisfying

$$
\sqrt{\phi(f(x, y))}[d(x, u)+d(y, v)] \leq f(x, y)
$$

such that

$$
f(u, v) \leq \phi(f(x, y))[d(x, u)+d(y, v)] .
$$

Then, $F$ admits a coupled fixed point, i.e., there exists $z=\left(z_{1}, z_{2}\right) \in X \times X$ such that $z_{1} \in F\left(z_{1}, z_{2}\right)$ and $z_{2} \in F\left(z_{2}, z_{1}\right)$.

In 2006, Bhaskar and Lakshmikantham [4] introduced the notion of a coupled fixed point and established some coupled fixed point theorems in partially ordered metric spaces. They have discussed the existence and uniqueness of a solution for a periodic boundary value problem. Lakshmikantham and Ćirić [5] proved coupled coincidence and coupled common fixed point theorems for nonlinear contractive mappings in partially ordered complete metric spaces using mixed $g$-monotone property. For more details on coupled fixed point theory, we refer the reader to [7-12] and the references therein. Here we study the existence of coupled coincidences for multi-valued nonlinear contractions using two different approaches, first is based on $\Delta$-symmetric property recently studied in [6] and second one is based on mixed $g$-monotone property studied by Lakshmikantham and Cirić [5]. The theorems presented extend certain results due to Ćirić [3], Samet and Vetro [6] and many others. We support the results by establishing an illustrative example.

\section{Coupled coincidences by $\Delta$-symmetric property}

Following is the main result of this section which generalizes the above mentioned results of Ćirić, and Samet and Vetro.

Theorem 2.1. Let $(X, d)$ be a metric space endowed with a partial order $\leqslant$ and $\Delta \neq \emptyset$. Suppose that $F: X \times X \rightarrow C L(X)$ is a $\Delta$-symmetric mapping, $g: X \rightarrow X$ is continuous, $g X$ is complete, the function $f: g(X) \times g(X) \rightarrow[0,+\infty)$ defined by

$$
f(g x, g y):=D(g x, F(x, y))+D(g y, F(y, x)) \text { for all } x, y \in X
$$


is lower semi-continuous and that there exists a function $\varphi:[0, \infty) \rightarrow[a, 1), 0<a<1$, satisfying

$$
\limsup _{r \rightarrow t^{+}} \phi(r)<1 \quad \text { for each } t \in[0,+\infty) .
$$

Assume that for any $(x, y) \in \Delta$ there exist $g u \in F(x, y)$ and $g v \in F(y, x)$ satisfying

$$
\sqrt{\phi(f(g x, g y))}[d(g x, g u)+d(g y, g v)] \leq f(g x, g y)
$$

such that

$$
f(g u, g v) \leq \phi(f(g x, g y))[d(g x, g u)+d(g y, g v)] .
$$

Then, $F$ and $g$ have a coupled coincidence point, i.e., there exists $g z=\left(g z_{1}, g z_{2}\right) \in X \times$ $X$ such that $g z_{1} \in F\left(z_{1}, z_{2}\right)$ and $g z_{2} \in F\left(z_{2}, z_{1}\right)$.

Proof. Since by the definition of $\varphi$ we have $\varphi(f(x, y))<1$ for each $(x, y) \in X \times X$, it follows that for any $(x, y) \in X \times X$ there exist $g u \in F(x, y)$ and $g v \in F(y, x)$ such that

$$
\sqrt{\phi(f(g x, g y))} d(g x, g u) \leq D(g x, F(x, y))
$$

and

$$
\sqrt{\phi(f(g x, g y))} d(g y, g v) \leq D(g y, F(y, x)) .
$$

Hence, for each $(x, y) \in X \times X$, there exist $g u \in F(x, y)$ and $g v \in F(y, x)$ satisfying (2.2). Let $\left(x_{0}, y_{0}\right) \in \Delta$ be arbitrary and fixed. By (2.2) and (2.3), we can choose $g x_{1} \in F\left(x_{0}\right.$, $\left.y_{0}\right)$ and $g y_{1} \in F\left(y_{0}, x_{0}\right)$ such that

$$
\sqrt{\phi\left(f\left(g x_{0}, g y_{0}\right)\right)}\left[d\left(g x_{0}, g x_{1}\right)+d\left(g y_{0}, g y_{1}\right)\right] \leq f\left(g x_{0}, g y_{0}\right)
$$

and

$$
f\left(g x_{1}, g y_{1}\right) \leq \phi\left(f\left(g x_{0}, g y_{0}\right)\right)\left[d\left(g x_{0}, g x_{1}\right)+d\left(g y_{0}, g y_{1}\right)\right] .
$$

From (2.4) and (2.5), we can get

$$
\begin{aligned}
f\left(g x_{1}, g y_{1}\right) & \leq \phi\left(f\left(g x_{0}, g y_{0}\right)\right)\left[d\left(g x_{0}, g x_{1}\right)+d\left(g y_{0}, g y_{1}\right)\right] \\
& =\sqrt{\phi\left(f\left(g x_{0}, g y_{0}\right)\right)}\left\{\sqrt{\phi\left(f\left(g x_{0}, g y_{0}\right)\right)}\left[d\left(g x_{0}, g x_{1}\right)+d\left(g y_{0}, g y_{1}\right)\right]\right\} \\
& \leq \sqrt{\phi\left(f\left(g x_{0}, g y_{0}\right)\right)} f\left(g x_{0}, g y_{0}\right) .
\end{aligned}
$$

Thus,

$$
f\left(g x_{1}, g y_{1}\right) \leq \sqrt{\phi\left(f\left(g x_{0}, g y_{0}\right)\right)} f\left(g x_{0}, g y_{0}\right) .
$$

Now, since $F$ is a $\Delta$-symmetric mapping and $\left(x_{0}, y_{0}\right) \in \Delta$, we have

$$
F\left(x_{0}, y_{0}\right) R F\left(y_{0}, x_{0}\right) \Rightarrow\left(x_{1}, y_{1}\right) \in \Delta .
$$

Also, by (2.2) and (2.3), we can choose $g x_{2} \in F\left(x_{1}, y_{1}\right)$ and $g y_{2} \in F\left(y_{1}, x_{1}\right)$ such that

$$
\sqrt{\phi\left(f\left(g x_{1}, g y_{1}\right)\right)}\left[d\left(g x_{1}, g x_{2}\right)+d\left(g y_{1}, g y_{2}\right)\right] \leq f\left(g x_{1}, g y_{1}\right)
$$

and

$$
f\left(g x_{2}, g y_{2}\right) \leq \phi\left(f\left(g x_{1}, g y_{1}\right)\right)\left[d\left(g x_{1}, g x_{2}\right)+d\left(g y_{1}, g y_{2}\right)\right] .
$$


Hence, we get

$$
f\left(g x_{2} g y_{2}\right) \leq \sqrt{\phi\left(f\left(g x_{1}, g y_{1}\right)\right)} f\left(g x_{1}, g y_{1}\right),
$$

with $\left(x_{2}, y_{2}\right) \in \Delta$.

Continuing this process we can choose $\left\{g x_{n}\right\} \subset X$ and $\left\{g y_{n}\right\} \subset X$ such that for all $n \in$ $\mathbb{N}$, we have

$$
\begin{aligned}
& \left(x_{n}, y_{n}\right) \in \Delta, \quad g x_{n+1} \in F\left(x_{n}, y_{n}\right), \quad g y_{n+1} \in F\left(y_{n}, x_{n}\right), \\
& \sqrt{\phi\left(f\left(g x_{n}, g y_{n}\right)\right)}\left[d\left(g x_{n}, g x_{x+1}\right)+d\left(g y_{n}, g y_{n+1}\right)\right] \leq f\left(g x_{n}, g y_{n}\right),
\end{aligned}
$$

and

$$
f\left(g x_{n+1}, g y_{n+1}\right) \leq \sqrt{\phi\left(f\left(g x_{n}, g y_{n}\right)\right)} f\left(g x_{n}, g y_{n}\right) .
$$

Now, we shall show that $f\left(g x_{n}, g y_{n}\right) \rightarrow 0$ as $n \rightarrow \infty$. We shall assume that $f\left(g x_{n}, g y_{n}\right)>$ 0 for all $n \in \mathbb{N}$, since if $f\left(g x_{n}, g y_{n}\right)=0$ for some $n \in \mathbb{N}$, then we get $D\left(g x_{n}, F\left(x_{n}, y_{n}\right)\right)=$ 0 which implies that $g x_{n} \in \overline{F\left(x_{n}, y_{n}\right)}=F\left(x_{n}, y_{n}\right)$ and $D\left(g y_{n}, F\left(y_{n}, x_{n}\right)\right)=0$ which implies that $g y_{n} \in F\left(y_{n}, x_{n}\right)$. Hence, in this case, $\left(x_{n}, y_{n}\right)$ is a coupled coincidence point of $F$ and $g$ and the assertion of the theorem is proved.

From (2.9) and $\varphi(t)<1$, we deduce that $\left\{f\left(g x_{n}, g y_{n}\right)\right\}$ is a strictly decreasing sequence of positive real numbers. Therefore, there is some $\delta \geq 0$ such that

$$
\lim _{n \rightarrow \infty} f\left(g x_{n}, g y_{n}\right)=\delta .
$$

Now, we will prove that $\delta=0$. Suppose that this is not the case; taking the limit on both sides of (2.9) and having in mind the assumption (2.1), we have

$$
\delta \leq \limsup _{f\left(g x_{n}, g y_{n}\right) \rightarrow \delta^{+}} \sqrt{\phi\left(f\left(g x_{n}, g y_{n}\right)\right)} \delta<\delta,
$$

a contradiction. Thus, $\delta=0$, that is,

$$
\lim _{n \rightarrow \infty} f\left(g x_{n}, g y_{n}\right)=0
$$

Now, let us prove that $\left\{g x_{n}\right\}$ and $\left\{g y_{n}\right\}$ are Cauchy sequences in $(X, d)$. Suppose that

$$
\alpha=\limsup _{f\left(g x_{n}, g y_{n}\right) \rightarrow 0^{+}} \sqrt{\phi\left(f\left(g x_{n}, g y_{n}\right)\right)} .
$$

Then, by assumption (2.1), we have $\alpha<1$. Let $q$ be such that $\alpha<q<1$. Then, there is some $n_{0} \in \mathbb{N}$ such that

$$
\sqrt{\phi\left(f\left(g x_{n}, g y_{n}\right)\right)}<q \text { for each } n \geq n_{0} .
$$

Thus, from (2.9), we get

$$
f\left(g x_{n+1}, g y_{n+1}\right) \leq q f\left(g x_{n}, g y_{n}\right) \text { for each } n \geq n_{0} .
$$

Hence, by induction,

$$
f\left(g x_{n+1}, g y_{n+1}\right) \leq q^{n+1-n_{0}} f\left(g x_{n 0}, g y_{n_{0}}\right) \text { for each } n \geq n_{0} .
$$


Since $\varphi(t) \geq a>0$ for all $t \geq 0$, from (2.8) and (2.11), we obtain

$$
d\left(g x_{n}, g x_{n+1}\right)+d\left(g y_{n}, g y_{n+1}\right) \leq \frac{1}{\sqrt{a}} q^{n-n_{0}} f\left(g x_{n_{0}}, g y_{n_{0}}\right) \quad \text { for each } n \geq n_{0} .
$$

From (2.12) and since $q<1$, we conclude that $\left\{g x_{n}\right\}$ and $\left\{g y_{n}\right\}$ are Cauchy sequences in $(X, d)$.

Now, since $g X$ is complete, there is a $w=\left(w_{1}, w_{2}\right) \in g X \times g X$ such that

$$
\lim _{n \rightarrow \infty} g x_{n}=w_{1}=g z_{1} \quad \text { and } \quad \lim _{n \rightarrow \infty} g y_{n}=w_{2}=g z_{2}
$$

for some $z_{1}, z_{2}$ in $X$. We now show that $z=\left(z_{1}, z_{2}\right)$ is a coupled coincidence point of $F$ and $g$. Since by assumption $f$ is lower semi-continuous so from (2.10), we get

$$
0 \leq f\left(g z_{1}, g z_{2}\right)=D\left(g z_{1}, F\left(z_{1}, z_{2}\right)\right)+D\left(g z_{2}, F\left(z_{2}, z_{1}\right)\right) \leq \liminf _{n \rightarrow \infty} f\left(g x_{n}, g y_{n}\right)=0 .
$$

Hence,

$$
D\left(g z_{1}, F\left(z_{1}, z_{2}\right)\right)=D\left(g z_{2}, F\left(z_{2}, z_{1}\right)\right)=0,
$$

which implies that $g z_{1} \in F\left(z_{1}, z_{2}\right)$ and $g z_{2} \in F\left(z_{2}, z_{1}\right)$, i.e., $z=\left(z_{1}, z_{2}\right)$ is a coupled coincidence point of $F$ and $g$. This completes the proof.

Now, we prove the following theorem.

Theorem 2.2. Let $(X, d)$ be a metric space endowed with a partial order $\leqslant$ and $\Delta \neq \emptyset$. Suppose that $F: X \times X \rightarrow C L(X)$ is a $\Delta$-symmetric mapping, $g: X \rightarrow X$ is continuous and $g X$ is complete. Suppose that the function $f: g X \times g X \rightarrow[0,+\infty)$ defined in Theorem 2.1 is lower semi-continuous and that there exists a function $\varphi:[0,+\infty) \rightarrow[a$, 1), $0<a<1$, satisfying

$$
\limsup _{r \rightarrow t+} \phi(r)<1 \quad \text { for each } t \in[0, \infty) .
$$

Assume that for any $(x, y) \in \Delta$, there exist $g u \in F(x, y)$ and $g \nu \in F(y, x)$ satisfying

$$
\sqrt{\phi(d(g x, g u)+d(g y, g v))}[d(g x, g u)+d(g y, g v)] \leq D(g x, F(x, y))+D(g y, F(y, x))
$$

such that

$$
D(g u, F(u, v))+D(g v, F(v, u)) \leq \phi(d(g x, g u)+d(g y, g v))[d(g x, g u)+d(g y, g v)] .
$$

Then, $F$ and $g$ have a coupled coincidence point, i.e., there exists $z=\left(z_{1}, z_{2}\right) \in X \times X$ such that $g z_{1} \in F\left(z_{1}, z_{2}\right)$ and $g z_{2} \in F\left(z_{2}, z_{1}\right)$.

Proof. Replacing $\varphi(f(x, y))$ with $\varphi(d(g x, g u)+d(g y, g v))$ and following the lines in the proof of Theorem 2.1, one can construct iterative sequences $\left\{x_{n}\right\} \subset X$ and $\left\{y_{n}\right\} \subset X$ such that for all $n \in \mathbb{N}$, we have

$$
\begin{aligned}
& \left(x_{n}, y_{n}\right) \in \Delta, \quad g x_{n+1} \in F\left(x_{n}, y_{n}\right), \quad g y_{n+1} \in F\left(y_{n}, x_{n}\right) \\
& \sqrt{\phi\left(d\left(g x_{n}, g x_{n+1}\right)+d\left(g y_{n}, g y_{n+1}\right)\right)}\left[d\left(g x_{n}, g x_{n+1}\right)+d\left(g y_{n}, g y_{n+1}\right)\right] \\
& \leq D\left(g x_{n}, F\left(x_{n}, y_{n}\right)\right)+D\left(g y_{n}, F\left(y_{n}, x_{n}\right)\right)
\end{aligned}
$$


and

$$
\begin{aligned}
& D\left(g x_{n+1}, F\left(x_{n+1}, y_{n+1}\right)\right)+D\left(g y_{n+1}, F\left(y_{n+1}, x_{n+1}\right)\right) \\
\leq & \sqrt{\varphi\left(d\left(g x_{n}, g x_{n+1}\right)+d\left(g y_{n}, g y_{n+1}\right)\right)}\left[D\left(g x_{n}, F\left(x_{n}, y_{n}\right)\right)+D\left(g y_{n}, F\left(y_{n}, x_{n}\right)\right)\right]
\end{aligned}
$$

for all $n \geq 0$. Again, following the lines of the proof of Theorem 2.1, we conclude that $\left\{D\left(g x_{n}, F\left(x_{n}, y_{n}\right)\right)+D\left(g y_{n}, F\left(y_{n}, x_{n}\right)\right)\right\}$ is a strictly decreasing sequence of positive real numbers. Therefore, there is some $\delta \geq 0$ such that

$$
\lim _{n \rightarrow+\infty}\left\{D\left(g x_{n}, F\left(x_{n}, y_{n}\right)\right)+D\left(g y_{n}, F\left(y_{n}, x_{n}\right)\right)=\delta\right.
$$

Since in our assumptions there appears $\varphi\left(d\left(g x_{n}, g x_{n+1}\right)+d\left(g y_{n}, g y_{n+1}\right)\right)$, we need to prove that $\left\{d\left(g x_{n}, g x_{n+1}\right)+d\left(g y_{n}, g y_{n+1}\right)\right\}$ admits a subsequence converging to a certain $\eta^{+}$for some $\eta \geq 0$. Since $\phi(t) \geq a>0$ for all $\mathrm{t} \geq 0$, from (2.18) we obtain

$$
d\left(g x_{n}, g x_{n+1}\right)+d\left(g y_{n}, g y_{n+1}\right) \leq \frac{1}{\sqrt{a}}\left[D\left(g x_{n}, F\left(x_{n}, y_{n}\right)\right)+D\left(g y_{n}, F\left(y_{n}, x_{n}\right)\right)\right] .
$$

From (2.20) and (2.21), we conclude that the sequence $\left\{d\left(g x_{n}, g x_{n+1}\right)+d\left(g y_{n}, g y_{n+1}\right)\right\}$ is bounded. Therefore, there is some $\theta \geq 0$ such that

$$
\liminf _{n \rightarrow+\infty}\left\{d\left(g x_{n}, g x_{n+1}\right)+d\left(g y_{n}, g y_{n+1}\right)\right\}=\theta
$$

Since $g x_{n+1} \in F\left(x_{n}, y_{n}\right)$ and $g y_{n+1} \in F\left(y_{n}, x_{n}\right)$, it follows that

$$
d\left(g x_{n}, g x_{n+1}\right)+d\left(g y_{n}, g y_{n+1}\right) \geq D\left(g x_{n}, F\left(x_{n}, y_{n}\right)\right)+D\left(g y_{n}, F\left(y_{n}, x_{n}\right)\right)
$$

for each $n \geq 0$. This implies that $\theta \geq \delta$. Now, we shall show that $\theta=\delta$. If we assume that $\delta=0$, then from (2.20) and (2.21) we have

$$
\lim _{n \rightarrow+\infty}\left\{d\left(g x_{n}, g x_{n+1}\right)+d\left(g y_{n}, g y_{n+1}\right)\right\}=0
$$

Thus, if $\delta=0$, then $\theta=\delta$. Suppose now that $\delta>0$ and suppose, to the contrary, that $\theta>\delta$. Then, $\theta-\delta>0$ and so from (2.20) and (2.22) there is a positive integer $n_{0}$ such that

$$
D\left(g x_{n}, F\left(x_{n}, y_{n}\right)\right)+D\left(g y_{n}, F\left(y_{n}, x_{n}\right)\right)<\delta+\frac{\theta-\delta}{4}
$$

and

$$
\theta-\frac{\theta-\delta}{4}<d\left(x_{n}, x_{n+1}\right)+d\left(y_{n}, y_{n+1}\right)
$$

for all $n \geq n_{0}$. Then, combining (2.18), (2.23) and (2.24) we get

$$
\begin{aligned}
& \sqrt{\varphi\left(d\left(g x_{n}, g x_{n+1}\right)+d\left(g y_{n}, g y_{n+1}\right)\right)}\left(\theta-\frac{\theta-\delta}{4}\right) \\
< & \sqrt{\varphi\left(d\left(g x_{n}, g x_{n+1}\right)+d\left(g y_{n}, g y_{n+1}\right)\right)}\left[d\left(g x_{n}, g x_{n+1}\right)+d\left(g y_{n}, g y_{n+1}\right)\right] \\
\leq & D\left(g x_{n}, F\left(x_{n}, y_{n}\right)\right)+D\left(g y_{n}, F\left(y_{n}, x_{n}\right)\right) \\
< & \delta+\frac{\theta-\delta}{4}
\end{aligned}
$$


for all $n \geq n_{0}$. Hence, we get

$$
\sqrt{\varphi\left(d\left(g x_{n}, g x_{n+1}\right)+d\left(g y_{n}, g y_{n+1}\right)\right)} \leq \frac{\theta+3 \delta}{3 \theta+\delta}
$$

for all $n \geq n_{0}$. Set $h=\frac{\theta+3 \delta}{3 \theta+\delta}<1$. Now, from (2.19) and (2.25), it follows that

$$
D\left(g x_{n+1}, F\left(x_{n+1}, y_{n+1}\right)\right)+D\left(g y_{n+1}, F\left(y_{n+1}, x_{n+1}\right)\right) \leq h\left[D\left(g x_{n}, F\left(x_{n}, y_{n}\right)\right)+D\left(g y_{n}, F\left(y_{n}, x_{n}\right)\right)\right]
$$

for all $n \geq n_{0}$. Finally, since we assume that $\delta>0$ and as $h<1$, proceeding by induction and combining the above inequalities, it follows that

$$
\begin{aligned}
\delta & \leq D\left(g x_{n_{0}+k_{0}}, F\left(x_{n_{0}+k_{0}}, y_{n_{0}+k_{0}}\right)\right)+D\left(g y_{n_{0}+k_{0}}, F\left(y_{n_{0}+k_{0}}, x_{n_{0}+k_{0}}\right)\right) \\
& \leq h^{k_{0}} D\left(g x_{n_{0}}, F\left(x_{n_{0}}, y_{n_{0}}\right)\right)+D\left(g y_{n_{0}}, F\left(y_{n_{0}}, x_{n_{0}}\right)\right)<\delta
\end{aligned}
$$

for a positive integer $k_{0}$, which is a contradiction to the assumption $\theta>\delta$ and so we must have $\theta=\delta$. Now, we shall show that $\theta=0$. Since

$$
\theta=\delta \leq D\left(g x_{n}, F\left(x_{n}, y_{n}\right)\right)+D\left(g y_{n}, F\left(y_{n}, x_{n}\right)\right) \leq d\left(g x_{n}, g x_{n+1}\right)+d\left(g y_{n}, g y_{n+1}\right),
$$

so we can read (2.22) as

$$
\liminf _{n \rightarrow+\infty}\left\{d\left(g x_{n}, g x_{n+1}\right)+d\left(g y_{n}, g y_{n+1}\right)\right\}=\theta^{+} .
$$

Thus, there exists a subsequence $\left\{d\left(g x_{n_{k}}, g x_{n_{k}+1}\right)+d\left(g y_{n_{k}}, g y_{n_{k}+1}\right)\right\}$ such that

$$
\lim _{k \rightarrow+\infty}\left\{d\left(g x_{n_{k}}, g x_{n_{k}+1}\right)+d\left(g y_{n_{k}}, g y_{n_{k}+1}\right)\right\}=\theta^{+} .
$$

Now, by (2.14), we have

$$
\limsup _{\left(d \left(g x_{\left.\left.n_{k^{\prime}}, g x_{n_{k}+1}\right)+d\left(g y_{n_{k^{\prime}}, g y_{n+1}}\right)\right) \rightarrow \theta^{+}}\right.\right.} \sqrt{\varphi\left(d\left(g x_{n_{k}} g x_{n_{k}+1}\right)+d\left(g y_{n_{k}} g y_{n_{k}+1}\right)\right)}<1 .
$$

From (2.19),

$$
\begin{aligned}
& D\left(g x_{n_{k}+1}, F\left(x_{n_{k}+1}, y_{n_{k}+1}\right)\right)+D\left(g y_{n_{k}+1}, F\left(y_{n_{k}+1}, x_{n_{k}+1}\right)\right) \\
\leq & \sqrt{\varphi\left(d\left(g x_{n_{k}}, g x_{n_{k}+1}\right)+d\left(g y_{n_{k}}, g y_{n_{k}+1}\right)\right)}\left[D\left(g x_{n_{k}}, F\left(x_{n_{k^{\prime}}}, y_{n_{k}}\right)\right)+D\left(g y_{n_{k}}, F\left(y_{n_{k^{\prime}}}, x_{n_{k}}\right)\right)\right] .
\end{aligned}
$$

Taking the limit as $k \rightarrow+\infty$ and using (2.20), we get

$$
\begin{aligned}
& \delta=\limsup _{k \rightarrow+\infty}\left\{D\left(g x_{n_{k}+1}, F\left(x_{n_{k}+1}, y_{n_{k}+1}\right)\right)+D\left(g y_{n_{k}+1}, F\left(y_{n_{k}+1}, x_{n_{k}+1}\right)\right)\right\} \\
& \leq\left(\limsup _{k \rightarrow+\infty} \sqrt{\varphi\left(d\left(g x_{n_{k}}, g x_{n_{k}+1}\right)+d\left(g y_{n_{k}} g y_{n_{k}+1}\right)\right)}\right) \\
& \left(\limsup _{k \rightarrow+\infty}\left\{D\left(g x_{n_{k}}, F\left(x_{n_{k}}, y_{n_{k}}\right)\right)+D\left(g y_{n_{k}}, F\left(y_{n_{k}}, x_{n_{k}}\right)\right)\right\}\right) \\
& =\left(\limsup _{\left(d\left(g x_{n_{k}}, g x_{n_{k}+1}\right)+d\left(g y_{n_{k}}, g y_{n_{k}+1}\right)\right) \rightarrow \theta^{+}} \sqrt{\varphi\left(d\left(g x_{n_{k}}, g x_{n_{k}+1}\right)+d\left(g y_{n_{k}} g y_{n_{k}+1}\right)\right)}\right) \delta .
\end{aligned}
$$

From the last inequality, if we suppose that $\delta>0$, we get

$$
1 \leq \limsup _{\left(d\left(g x_{n_{k}}, g x_{n_{k}+1}\right)+d\left(g y_{n_{k}}, g y_{k^{+}}\right)\right) \rightarrow \theta+} \sqrt{\varphi\left(d\left(g x_{n_{k}}, g x_{n_{k}+1}\right)+d\left(g y_{n_{k}}, g y_{n_{k}+1}\right)\right)}
$$


a contradiction with (2.26). Thus, $\delta=0$. Then, from (2.20) and (2.21) we have

$$
\alpha=\limsup _{\left(d\left(g x_{n}, g x_{n+1}\right)+d\left(g y_{n}, g y_{n+1}\right)\right) \rightarrow 0+} \sqrt{\varphi\left(d\left(g x_{n}, g x_{n+1}\right)+d\left(g y_{n}, g y_{n+1}\right)\right)}<1 .
$$

Once again, proceeding as in the proof of Theorem 2.1, one can prove that $\left\{g x_{n}\right\}$ and $\left\{g y_{n}\right\}$ are Cauchy sequences in $g X$ and that $z=\left(z_{1}, z_{2}\right) \in X \times X$ is a coupled coincidence point of $F, g$, i.e.

$$
g z_{1} \in F\left(z_{1}, z_{2}\right) \quad \text { and } \quad g z_{2} \in F\left(z_{2}, z_{1}\right) .
$$

Example 2.3. Suppose that $X=[0,1]$, equipped with the usual metric $d: X \times X \rightarrow[0$, $+\infty)$, and $G:[0,1] \rightarrow[0,1]$ is the mapping defined by

$$
G(x)=M \quad \text { for all } x \in[0,1],
$$

where $M$ is a constant in [0,1]. Let $F: X \times X \rightarrow C L(X)$ be defined as

$$
F(x, y)= \begin{cases}\frac{x^{2}}{4} & \text { if } y \in\left[0, \frac{15}{32}\right) \cup\left(\frac{15}{32}, 1\right], \\ \left\{\frac{15}{96}, \frac{1}{5}\right\} & \text { if } y=\frac{15}{32} .\end{cases}
$$

Then, $\Delta=[0,1] \times[0,1]$ and $F$ is a $\Delta$-symmetric mapping. Define now $\phi:[0,+\infty) \rightarrow$ $[0,1)$ by

$$
\varphi(t)=\left\{\begin{array}{l}
\frac{11}{12} t \text { if } t \in\left[0, \frac{2}{3}\right] \\
\frac{11}{18} \text { if } t \in\left(\frac{2}{3},+\infty\right) .
\end{array}\right.
$$

Let $g:[0,1] \rightarrow[0,1]$ be defined as $g x=x^{2}$. Now, we shall show that $F(x, y)$ satisfies all the assumptions of Theorem 2.2. Let

$$
f(x, y)= \begin{cases}\sqrt{x}+\sqrt{y}-\frac{1}{4}(x+y) & \text { if } x, y \in\left[0, \frac{15}{32}\right) \cup\left(\frac{15}{32}, 1\right] \\ \sqrt{x}-\frac{1}{4} x+\frac{43}{160} & \text { if } x \in\left[0, \frac{15}{32}\right) \cup\left(\frac{15}{32}, 1\right] \text { and } y=\frac{15}{32} \\ \sqrt{y}-\frac{1}{4} y+\frac{43}{160} & \text { if } y \in\left[0, \frac{15}{32}\right) \cup\left(\frac{15}{32}, 1\right] \text { and } x=\frac{15}{32} \\ \frac{43}{80} & \text { if } x=y=\frac{15}{32}\end{cases}
$$

It is easy to see that the function

$$
f(g x, g y)= \begin{cases}x+y-\frac{1}{4}\left(x^{2}+y^{2}\right) & \text { if } x, y \in\left[0, \frac{15}{32}\right) \cup\left(\frac{15}{32}, 1\right], \\ x-\frac{1}{4} x^{2}+\frac{43}{160} & \text { if } x \in\left[0, \frac{15}{32}\right) \cup\left(\frac{15}{32}, 1\right] \text { and } y=\frac{15}{32}, \\ y-\frac{1}{4} y^{2}+\frac{43}{160} & \text { if } y \in\left[0, \frac{15}{32}\right) \cup\left(\frac{15}{32}, 1\right] \text { and } x=\frac{15}{32}, \\ \frac{43}{80} & \text { if } x=y=\frac{15}{32}\end{cases}
$$

is lower semi-continuous. Therefore, for all $x, y \in[0,1]$ with $x, y \neq \frac{15}{32}$, there exist $g u \in F(x, y)=\left\{\frac{x^{2}}{4}\right\}$ and $g v \in F(y, x)=\left\{\frac{y^{2}}{4}\right\}$ such that

$$
\begin{aligned}
D(g u, F(u, v))+D(g v, F(v, u)) & =\frac{x^{2}}{4}-\frac{x^{4}}{64}+\frac{y^{2}}{4}-\frac{y^{4}}{64} \\
& =\frac{1}{4}\left[\left(x+\frac{x^{2}}{4}\right)\left(x-\frac{x^{2}}{4}\right)+\left(y+\frac{y^{2}}{4}\right)\left(y-\frac{y^{2}}{4}\right)\right] \\
& \leq \frac{1}{4}\left[\left(x+\frac{x^{2}}{4}\right) d(g x, g u)+\left(y+\frac{y^{2}}{4}\right) d(g y, g v)\right] \\
& \leq \frac{1}{2} \max \left\{x+\frac{x^{2}}{4}, y+\frac{y^{2}}{4}\right\}[d(g x, g u)+d(g y, g v)] \\
& <\frac{11}{12} \max \left\{\left(x-\frac{x^{2}}{4}\right),\left(y-\frac{y^{2}}{4}\right)\right\}[d(g x, g u)+d(g y, g v)] \\
& \leq \varphi(d(g x, g u)+d(g y, g v))[d(g x, g u)+d(g y, g v)] .
\end{aligned}
$$


Thus, for $\mathrm{x}, \mathrm{y} \in[0,1]$ with $x, y \neq \frac{15}{32}$, the conditions (2.15) and (2.16) are satisfied. Following similar arguments, one can easily show that conditions (2.15) and (2.16) are also satisfied for $x \in\left[0, \frac{15}{32}\right) \cup\left(\frac{15}{32}, 1\right]$ and $y=\frac{15}{32}$. Finally, for $x=y=\frac{15}{32}$, if we assume that $g u=g v=\frac{15}{96}$, it follows that $d(g x, g u)+d(g y, g v)=\frac{15}{24}$.

Consequently, we get

$$
\begin{aligned}
\sqrt{\varphi(d(g x, g u)+d(g y, g v))}[d(g x, g u)+d(g y, g v)] & =\sqrt{\frac{11}{24} \cdot \frac{15}{24}} \cdot \frac{15}{24} \\
& <\frac{43}{80}=D(g x, F(x, y))+D(g y, F(y, x))
\end{aligned}
$$

and

$$
\begin{aligned}
D(g u, F(u, v))+D(g v, F(v, u)) & =2\left|\frac{15}{96}-\frac{1}{4}\left(\frac{15}{96}\right)^{2}\right| \\
& <\frac{11}{12} \cdot \frac{15}{24} \cdot \frac{15}{24} \\
& =\varphi(d(g x, g u)+d(g y, g v))[d(g x, g u)+d(g y, g v)] .
\end{aligned}
$$

Thus, we conclude that all the conditions of Theorem 2.2 are satisfied, and $F, g$ admits a coupled coincidence point $z=(0,0)$.

\section{Coupled coincidences by mixed $\boldsymbol{g}$-monotone property}

Recently, there have been exciting developments in the field of existence of fixed points in partially ordered metric spaces (cf. [13-24]). Using the concept of commuting maps and mixed $g$-monotone property, Lakshmikantham and Ćirić in [5] established the existence of coupled coincidence point results to generalize the results of Bhaskar and Lakshmikantham [4]. Choudhury and Kundu generalized these results to compatible maps. In this section, we shall extend the concepts of commuting, compatible maps and mixed $g$-monotone property to the case when $F$ is multi-valued map and prove the extension of the above mentioned results.

Analogous with mixed monotone property, Lakshmikantham and Ćirić [5] introduced the following concept of a mixed $g$-monotone property.

Definition 3.1. Let $(X, \preccurlyeq)$ be a partially ordered set and $F: X \times X \rightarrow X$ and $g: X \rightarrow$ $X$. We say $F$ has the mixed g-monotone property if $F$ is monotone g-non-decreasing in its first argument and is monotone g-non-increasing in its second argument, that is, for any $x, y \in X$,

$$
x_{1}, x_{2} \in X, g\left(x_{1}\right) \preccurlyeq g\left(x_{2}\right) \quad \text { implies } \quad F\left(x_{1}, y\right) \preccurlyeq F\left(x_{2}, y\right)
$$

and

$$
y_{1}, y_{2} \in X, g\left(y_{1}\right) \preccurlyeq g\left(y_{2}\right) \text { implies } F\left(x, y_{1}\right) \succcurlyeq F\left(x, y_{2}\right) .
$$

Definition 3.2. Let $(X, \preccurlyeq)$ be a partially ordered set, $F: X \times X \rightarrow C L(X)$ and let $g: X$ $\rightarrow X$ be a mapping. We say that the mapping $F$ has the mixed g-monotone property if, for all $x_{1}, x_{2}, y_{1}, y_{2} \in X$ with $g x_{1} \leqslant g x_{2}$ and $g y_{1} \geqslant g y_{2}$, we get for all $g u_{1} \in F\left(x_{1}, y_{1}\right)$ there exists $g u_{2} \in F\left(x_{2}, y_{2}\right)$ such that $g u_{1} \leqslant g u_{2}$ and for all $g v_{1} \in F\left(y_{1}, x_{1}\right)$ there exists $g v_{2} \in F\left(y_{2}, x_{2}\right)$ such that $g v_{1} \geqslant z g v_{2}$. 
Definition 3.3. The mapping $F: X \times X \rightarrow C B(X)$ and $g: X \rightarrow X$ are said to be compatible if

$$
\lim _{n \rightarrow \infty} H\left(g\left(F\left(x_{n}, y_{n}\right)\right), F\left(g x_{n}, g y_{n}\right)\right)=0
$$

and

$$
\lim _{n \rightarrow \infty} H\left(g\left(F\left(y_{n}, x_{n}\right)\right), F\left(g y_{n}, g x_{n}\right)\right)=0,
$$

whenever $\left\{x_{n}\right\}$ and $\left\{y_{n}\right\}$ are sequences in $X$, such that $x=\lim _{n \rightarrow \infty} g x_{n} \in \lim _{n \rightarrow \infty} F\left(x_{n}\right.$, $\left.y_{n}\right)$ and $y=\lim _{n \rightarrow \infty} g y_{n} \in \lim _{n \rightarrow \infty} F\left(y_{n}, x_{n}\right)$, for all $x, y \in X$ are satisfied.

Definition 3.4. The mapping $F: X \times X \rightarrow C B(X)$ and $g: X \rightarrow X$ are said to be commuting if $g F(x, y) \subseteq F(g x, g y)$ for all $x, y \in X$.

Lemma 3.1. [1] If $A, B \in C B(X)$ with $H(A, B)<\epsilon$, then for each $a \in A$ there exists an element $b \in B$ such that $d(a, b)<\epsilon$.

Lemma 3.2. [1] Let $\left\{A_{n}\right\}$ be a sequence in $C B(X)$ and $\lim _{n \rightarrow \infty} H\left(A_{n}, A\right)=0$ for $A \in$ $C B(X)$. If $x_{n} \in A_{n}$ and $\lim _{n \rightarrow \infty} d\left(x_{n}, x\right)=0$, then $x \in A$.

Let $(X, \preccurlyeq)$ be a partially ordered set and $d$ be a metric on $X$ such that $(X, d)$ is a complete metric space. We define the partial order on the product space $X \times X$ as:

for $(u, v),(x, y) \in X \times X,(u, v) \leqslant(x, y)$ if and only if $u \leqslant x, v \geqslant y$.

The product metric on $X \times X$ is defined as

$$
d\left(\left(x_{1}, y_{1}\right),\left(x_{2}, y_{2}\right)\right):=d\left(x_{1}, x_{2}\right)+d\left(y_{1}, y_{2}\right) \text { for all } x_{i}, y_{i} \in X(i=1,2) .
$$

For notational convenience, we use the same symbol $d$ for the product metric as well as for the metric on $X$.

We begin with the following result that gives the existence of a coupled coincidence point for compatible maps $F$ and $g$ in partially ordered metric spaces, where $F$ is the multi-valued mappings.

Theorem 3.1. Let $F: X \times X \rightarrow C B(X), g: X \rightarrow X$ be such that:

(1) there exists $\kappa \in(0,1)$ with

$$
H(F(x, y), F(u, v)) \leq \frac{k}{2} d((g x, g y),(g u, g v)) \quad \text { for all }(g x, g y) \succcurlyeq(g u, g v) ;
$$

(2) if $g x_{1} \leqslant g x_{2}, g y_{2} \leqslant g y_{1}, x_{i}, y_{i} \in X(i=1,2)$, then for all $g u_{1} \in F\left(x_{1}, y_{1}\right)$ there exists $g u_{2} \in F\left(x_{2}, y_{2}\right)$ with $g u_{1} \leqslant g u_{2}$ and for all $g v_{1} \in F\left(y_{1}, x_{1}\right)$ there exists $g v_{2} \in F\left(y_{2}, x_{2}\right)$ with $g v_{2} \leqslant g v_{1}$ provided $d\left(\left(g u_{1}, g v_{1}\right),\left(g u_{2}, g v_{2}\right)\right)<1$; i.e. $F$ has the mixed $g$-monotone property, provided $d\left(\left(g u_{1}, g v_{1}\right),\left(g u_{2}, g v_{2}\right)\right)<1$;

(3) there exists $x_{0}, y_{0} \in X$, and some $g x_{1} \in F\left(x_{0}, y_{0}\right), g y_{1} \in F\left(y_{0}, x_{0}\right)$ with $g x_{0} \leqslant g x_{1}$, $g y_{0} \geqslant g y_{1}$ such that $d\left(\left(g x_{0}, g y_{0}\right),\left(g x_{1}, g y_{1}\right)\right)<1-\kappa$, where $\kappa \in(0,1)$;

(4) if a non-decreasing sequence $\left\{x_{n}\right\} \rightarrow x$, then $x_{n} \leq x$ for all $n$ and if a non-increasing sequence $\left\{y_{n}\right\} \rightarrow y$, then $y \leq y_{n}$ for all $n$ and $g X$ is complete.

Then, $F$ and $g$ have a coupled coincidence point. 
Proof. Let $x_{0}, y_{0} \in X$ then by (3) there exists $g x_{1} \in F\left(x_{0}, y_{0}\right), g y_{1} \in F\left(y_{0}, x_{0}\right)$ with $g x_{0}$ $\leqslant g x_{1}, g y_{0} \geqslant g y_{1}$ such that

$$
d\left(\left(g x_{0}, g y_{0}\right),\left(g x_{1}, g y_{1}\right)\right)<1-\kappa .
$$

Since $\left(g x_{0}, g y_{0}\right) \preccurlyeq\left(g x_{1}, g y_{1}\right)$ using (1) and (3.3), we have

$$
H\left(F\left(x_{0}, y_{0}\right), F\left(x_{1}, y_{1}\right)\right) \leq \frac{\kappa}{2} d\left(\left(g x_{0}, g y_{0}\right),\left(g x_{1}, g y_{1}\right)\right)<\frac{\kappa}{2}(1-\kappa)
$$

and similarly

$$
H\left(F\left(y_{0}, x_{0}\right), F\left(y_{1}, x_{1}\right)\right) \leq \frac{\kappa}{2}(1-\kappa) .
$$

Using (2) and Lemma 3.1, we have the existence of $g x_{2} \in F\left(x_{1}, y_{1}\right), g y_{2} \in F\left(y_{1}, x_{1}\right)$ with $x_{1} \leqslant x_{2}$ and $y_{1} \geqslant y_{2}$ such that

$$
d\left(g x_{1}, g x_{2}\right) \leq \frac{\kappa}{2}(1-\kappa)
$$

and

$$
d\left(g y_{1}, g y_{2}\right) \leq \frac{\kappa}{2}(1-\kappa)
$$

From (3.4) and (3.5),

$$
d\left(\left(g x_{1}, g y_{1}\right),\left(g x_{2}, g y_{2}\right)\right) \leq \kappa(1-\kappa) .
$$

Again by (1) and (3.6), we have

$$
H\left(F\left(x_{1}, y_{1}\right), F\left(x_{2}, y_{2}\right)\right) \leq \frac{\kappa^{2}}{2}(1-\kappa)
$$

and

$$
D\left(F\left(y_{1}, x_{1}\right), F\left(y_{2}, x_{2}\right)\right) \leq \frac{\kappa^{2}}{2}(1-\kappa) .
$$

From Lemma 3.1 and (2), we have the existence of $g x_{3} \in F\left(x_{2}, y_{2}\right), g y_{3} \in F\left(y_{2}, x_{2}\right)$ with $g x_{2} \preccurlyeq g x_{3}, g y_{2} \geqslant g y_{3}$ such that

$$
d\left(g x_{2}, g x_{3}\right) \leq \frac{\kappa^{2}}{2}(1-\kappa)
$$

and

$$
d\left(g \gamma_{2}, g \gamma_{3}\right) \leq \frac{\kappa^{2}}{2}(1-\kappa)
$$

It follows that

$$
d\left(\left(g x_{2}, g y_{2}\right),\left(g x_{3}, g y_{3}\right)\right) \leq \kappa^{2}(1-\kappa) .
$$

Continuing in this way we obtain $g x_{n+1} \in F\left(x_{n}, y_{n}\right), g y_{n+1} \in F\left(y_{n}, x_{n}\right)$ with $g x_{n} \preccurlyeq g x_{n+1}, g y_{n} \succcurlyeq g y_{n_{1}}$ such that 


$$
d\left(g x_{n}, g x_{n+1}\right) \leq \frac{\kappa^{n}}{2}(1-\kappa)
$$

and

$$
d\left(g y_{n}, g y_{n+1}\right) \leq \frac{\kappa^{n}}{2}(1-\kappa) .
$$

Thus,

$$
d\left(\left(g x_{n}, g y_{n}\right),\left(g x_{n+1}, g y_{n+1}\right)\right) \leq \kappa^{n}(1-\kappa) .
$$

Next, we will show that $\left\{g x_{n}\right\}$ is a Cauchy sequence in $X$. Let $m>n$. Then,

$$
\begin{aligned}
d\left(g x_{n}, g x_{m}\right) & \leq d\left(g x_{n}, g x_{n+1}\right)+d\left(g x_{n+1}, g x_{n+2}\right)+d\left(g x_{n+2}, g x_{n+3}\right)+\cdots+d\left(g x_{m-1}, g x_{m}\right) \\
& \leq\left[\kappa^{n}+\kappa^{n+1}+\kappa^{n+2}+\cdots+\kappa^{m-1}\right] \frac{(1-\kappa)}{2} \\
& =\kappa^{n}\left[1+\kappa+\kappa^{2}+\cdots+\kappa^{m-n-1}\right] \frac{(1-\kappa)}{2} \\
& =\kappa^{n}\left[\frac{1-\kappa^{m-n}}{1-\kappa}\right] \frac{(1-\kappa)}{2} \\
& =\frac{\kappa^{n}}{2}\left(1-\kappa^{m-n}\right)<\frac{\kappa^{n}}{2},
\end{aligned}
$$

because $\kappa \in(0,1), 1-\kappa^{m-n}<1$. Therefore, $d\left(g x_{n}, g x_{m}\right) \rightarrow 0$ as $n \rightarrow \infty$ implies that $\left\{g x_{n}\right\}$ is a Cauchy sequence. Similarly, we can show that $\left\{g y_{n}\right\}$ is also a Cauchy sequence in $X$. Since $g X$ is complete, there exists $x, y \in X$ such that $g x_{n} \rightarrow g x$ and $g y_{n} \rightarrow g y$ as $n$ $\rightarrow \infty$. Finally, we have to show that $g x \in F(x, y)$ and $g y \in F(y, x)$.

Since $\left\{g x_{n}\right\}$ is a non-decreasing sequence and $\left\{g y_{n}\right\}$ is a non-increasing sequence in $X$ such that $g x_{n} \rightarrow x$ and $g y_{n} \rightarrow y$ as $n \rightarrow \infty$, therefore we have $g x_{n} \leqslant x$ and $g y_{n} \geqslant y$ for all $n$. As $n \rightarrow \infty$, (1) implies that

$$
H\left(F\left(x_{n}, y_{n}\right), F(x, y)\right) \leq \frac{\kappa}{2} d\left(\left(g x_{n}, g y_{n}\right),(g x, g y)\right) \rightarrow 0 .
$$

Since $g x_{n+1} \in F\left(x_{n}, y_{n}\right)$ and $\lim _{n \rightarrow \infty} d\left(g x_{n+1}, g x\right)=0$, it follows using Lemma 3.2 that $g x \in F(x, y)$. Again by $(1)$,

$$
H\left(F\left(y_{n}, x_{n}\right), F(y, x)\right) \leq \frac{\kappa}{2} d\left(\left(g y_{n}, g x_{n}\right),(g y, g x)\right) \rightarrow 0 .
$$

Since $g y_{n+1} \in F\left(y_{n}, x_{n}\right)$ and $\lim _{n \rightarrow \infty} d\left(g y_{n+1}, g y\right)=0$, it follows using Lemma 3.2 that $g y \in F(y, x)$.

Theorem 3.2. Let $F: X \times X \rightarrow C B(X), g: X \rightarrow X$ be such that conditions (1)-(3) of Theorem 3.1 hold. Let $X$ be complete, $F$ and $g$ be continuous and compatible. Then, $F$ and $g$ have a coupled coincidence point.

Proof. As in the proof of Theorem 3.1, we obtain the Cauchy sequences $\left\{g x_{n}\right\}$ and $\left\{g y_{n}\right\}$ in $X$. Since $X$ is complete, there exists $x, y \in X$ such that $g x_{n} \rightarrow x$ and $g y_{n} \rightarrow y$ as $n \rightarrow \infty$. Finally, we have to show that $g x \in F(x, y)$ and $g y \in F(y, x)$. Since the mapping $F: X \times X \rightarrow C B(X)$ and $g: X \rightarrow X$ are compatible, we have

$$
\lim _{n \rightarrow \infty} H\left(g\left(F\left(x_{n}, y_{n}\right)\right), F\left(g x_{n}, g y_{n}\right)\right)=0,
$$


because $\left\{x_{n}\right\}$ is a sequence in $X$, such that $x=\lim _{n \rightarrow \infty} g x_{n+1} \in \lim _{n \rightarrow \infty} F\left(x_{n}, y_{n}\right)$ is satisfied. For all $n \geq 0$, we have

$$
D\left(g x, F\left(g x_{n}, g y_{n}\right)\right) \leq D\left(g x, g F\left(x_{n}, y_{n}\right)\right)+H\left(g F\left(x_{n}, y_{n}\right), F\left(g x_{n}, g y_{n}\right)\right) .
$$

Taking the limit as $n \rightarrow \infty$, and using the fact that $g$ and $F$ are continuous, we get, $D$ $(g x, F(x, y))=0$, which implies that $g x \in F(x, y)$.

Similarly, since the mapping $F$ and $g$ are compatible, we have

$$
\lim _{n \rightarrow \infty} H\left(g\left(F\left(y_{n}, x_{n}\right)\right), F\left(g y_{n}, g x_{n}\right)\right)=0,
$$

because $\left\{y_{n}\right\}$ is a sequence in $X$, such that $y=\lim _{n \rightarrow \infty} g y_{n+1} \in \lim _{n \rightarrow \infty} F\left(y_{n}, x_{n}\right)$ is satisfied. For all $n \geq 0$, we have

$$
D\left(g y_{1} F\left(g y_{n}, g x_{n}\right)\right) \leq D\left(g y_{1} g F\left(y_{n}, x_{n}\right)\right)+H\left(g F\left(y_{n}, x_{n}\right), F\left(g y_{n}, g x_{n}\right)\right) .
$$

Taking the limit as $\mathrm{n} \rightarrow \infty$, and using the fact that $g$ and $F$ are continuous, we get $D$ $(g y, F(y, x))=0$, which implies that $g y \in F(y, x)$.

As commuting maps are compatible, we obtain the following;

Theorem 3.3. Let $F: X \times X \rightarrow C B(X), g: X \rightarrow X$ be such that conditions (1)-(3) of Theorem 3.1 hold. Let $X$ be complete, $F$ and $g$ be continuous and commuting. Then, $F$ and $g$ have a coupled coincidence point.

\section{Authors' contributions}

The authors have equitably contributed in obtaining the new results presented in this article. All authors read and approved the final manuscript.

\section{Competing interests}

The authors declare that they have no competing interests.

Received: 30 June 2011 Accepted: 22 November 2011 Published: 22 November 2011

\section{References}

1. Nadler, SB: Multivalued contraction mappings. Pacific J Math. 30, 475-488 (1969)

2. Mizoguchi, N, Takahashi, W: Fixed point theorems for multivalued mappings on complete metric spaces. J Math Anal Appl. 141, 177-188 (1989). doi:10.1016/0022-247X(89)90214-X

3. Ćirić, LjB: Multi-valued nonlinear contraction mappings. Nonlinear Anal. 71, 2716-2723 (2009). doi:10.1016/j. na.2009.01.116

4. Bhaskar, TG, Lakshmikantham, V: Fixed point theorems in partially ordered metric spaces and applications. Nonlinear Anal. 65, 1379-1393 (2006). doi:10.1016/j.na.2005.10.017

5. Lakshmikantham, V, Cirić, LjB: Coupled fixed point theorems for nonlinear contractions in partially ordered metric spaces. Nonlinear Anal. 70, 4341-4349 (2009). doi:10.1016/j.na.2008.09.020

6. Samet, B, Vetro, C: Coupled fixed point theorems for multi-valued nonlinear contraction mappings in partially ordered metric spaces. Nonlinear Anal. 74, 4260-4268 (2011). doi:10.1016/j.na.2011.04.007

7. Abbas, M, llic, D, Khan, MA: Coupled coincidence point and coupled common fixed point theorems in partially ordered metric spaces with w-distance. Fixed Point Theory Appl 11 (2010). 2010, Article ID 134897

8. Beg, I, Butt, AR: Coupled fixed points of set valued mappings in partially ordered metric spaces. J Nonlinear Sci Appl. 3 179-185 (2010)

9. Choudhury, BS, Kundu, A: A coupled coincidence point result in partially ordered metric spaces for compatible mappings. Nonlinear Anal. 73, 2524-2531 (2010). doi:10.1016/j.na.2010.06.025

10. Cho, YJ, Shah, MH, Hussain, N: Coupled fixed points of weakly F-contractive mappings in topological spaces. Appl Math Lett. 24, 1185-1190 (2011). doi:10.1016/j.aml.2011.02.004

11. Harjani, J, Lopez, B, Sadarangani, K: Fixed point theorems for mixed monotone operators and applications to integral equations. Nonlinear Anal. 74, 1749-1760 (2011). doi:10.1016/j.na.2010.10.047

12. Hussain, N, Shah, MH, Kutbi, MA: Coupled coincidence point theorems for nonlinear contractions in partially ordered quasi-metric spaces with a Q-function. Fixed Point Theory Appl 21 (2011). 2011, Article ID 703938

13. Agarwal, RP, El-Gebeily, MA, O'Regan, D: Generalized contractions in partially ordered metric spaces. Appl Anal. 87, 1-8 (2008). doi:10.1080/00036810701714164

14. Ćirić, LjB: Fixed point theorems for multi-valued contractions in complete metric spaces. J Math Anal Appl. 348 , 499-507 (2008). doi:10.1016/j.jmaa.2008.07.062

15. Du, WS: Coupled fixed point theorems for nonlinear contractions satisfied Mizoguchi-Takahashi's condition in quasiordered metric spaces. Fixed Point Theory Appl 9 (2010). 2010, Article ID 876372 
16. Harjani, J, Sadarangani, K: Fixed point theorems for weakly contractive mappings in partially ordered sets. Nonlinear Anal. 71, 3403-3410 (2008)

17. Harjani, J, Sadarangani, K: Generalized contractions in partially ordered metric spaces and applications to ordinary differential equations. Nonlinear Anal. 72, 1188-1197 (2010). doi:10.1016/.j.na.2009.08.003

18. Nieto, JJ, Rodriguez-Lopez, R: Contractive mapping theorems in partially ordered sets and applications to ordinary differential equations, Order. 22, 223-239 (2005)

19. Nieto, JJ, Rodriguez-Lopez, R: Existence and uniqueness of fixed point in partially ordered sets and applications to ordinary differential equations. Acta Math Sin (Engl Ser). 23, 2205-2212 (2007). doi:10.1007/s10114-005-0769-0

20. Nieto, JJ, Pouso, RL, Rodriquez-Lopez, R: Fixed point theorems in ordered abstract spaces. Proc Am Math Soc. 135, 2505-2517 (2007). doi:10.1090/50002-9939-07-08729-1

21. Ran, $A C M$, Reurings, $M C B$ : A fixed point theorem in partially ordered sets and some applications to matrix equations. Proc Am Math Soc. 132, 1435-1443 (2004). doi:10.1090/50002-9939-03-07220-4

22. Saadati, R, Vaezpour, SM: Monotone generalized weak contractions in partially ordered metric spaces. Fixed Point Theory. 11, 375-382 (2010)

23. Saadati, R, Vaezpour, SM, Vetro, P, Rhoades, BE: Fixed point theorems in generalized partially ordered G-metric spaces. Math Comput Modelling. 52, 797-801 (2010). doi:10.1016/j.mcm.2010.05.009

24. Samet, B: Coupled fixed point theorems for a generalized Meir-Keeler contraction in partially ordered metric spaces. Nonlinear Anal. 72, 4508-4517 (2010). doi:10.1016/j.na.2010.02.026

doi:10.1186/1687-1812-2011-82

Cite this article as: Hussain and Alotaibi: Coupled coincidences for multi-valued contractions in partially ordered metric spaces. Fixed Point Theory and Applications 2011 2011:82.

\section{Submit your manuscript to a SpringerOpen ${ }^{\odot}$} journal and benefit from:

- Convenient online submission

- Rigorous peer review

- Immediate publication on acceptance

- Open access: articles freely available online

- High visibility within the field

- Retaining the copyright to your article

Submit your next manuscript at $\boldsymbol{\triangleright}$ springeropen.com 